\title{
A Study on an Evaluation Tool for the Management of Liver Disease by Occupational Health Management Agencies
}

\author{
Moon-Hee Jung and Chung-Min CHo \\ Department of Nursing, College of Medicine, Hanyang University
}

\begin{abstract}
A Study on an Evaluation Tool for the Management of Liver Disease by Occupational Health Management Agencies: Moon-Hee Jung, et al. Department of Nursing, College of Medicine, Hanyang University-The management of liver disease is one of the most important services of occupational health nurses. It is therefore important to also develop an evaluation tool for it in order to improve the quality of nursing activities provided by occupational health management agencies. This study was conducted to develop such a standardized evaluation tool for the management of liver disease performed by occupational health nurses. The contents of the tool were made into the form of a questionnaire after the validity test and preliminary survey on the basis of interviews with occupational health nurses and workers given between Dec. 1, 1997 and May 31, 1998. The test for the reliability and validity of the developed tool was conducted on 106 nurses placed by occupational health management agencies and 136 workers diagnosed with liver disease, between July 30 , 1998 and Sep. 30, 1998. 61 nurses' answers and 22 workers' answers were used for a test-retest analysis. The data were analyzed by means of Cronbach's alpha coefficients, Pearson's correlations, Spearman's correlations and multiple regression analysis in SPSS/ $\mathrm{PC}+$. The results are as follows; 1.25 items in the tool for nurses and 17 in the tool for workers were finally selected as items in the questionnaire. And each item was in the form of a 5-point scale. 2. Cronbach's alpha and test-retest correlation coefficient of the finally developed tool were higher than 0.70 and its explanatory power for the common variables of each factor was higher than $90 \%$, which proved that its reliability and content validity was fairly high. The tool developed in this study is therefore expected to be useful in evaluating the services for the management of liver disease provided by occupational health nurses
\end{abstract}

Received Aug 17, 1999; Accepted Nov 28, 1999

Correspondence to: $M$.-H. Jung. Dept. of Nursing, College of Medicine, Hanyang University, 17 Hangdang-dong, Seongdongku, 133-79l, Seoul, Korea in group health practice.

(J Occup Health 2000; 42: 72-78)

Key words: Evaluation tool, Management of liver disease, Occupational health nurse, Occupational Health Management Agencies

In Korea, workplaces with less than three hundred employees which cannot afford to employ full-time health managers may entrust their health management affairs to occupational health management agencies authorized by the Ministry of Labor. Health managers (doctors, nurses and industrial hygienists) placed by those occupational health management agencies provide them with occupational health services. An occupational health nurse, as a health manager, should visit each workplace more than once per month according to the regulations of the related laws ${ }^{1)}$. This program has been in force since 1988.

As of 1999, there are a total of 69 occupational health management agencies throughout the nation ${ }^{2)}$. They take charge of health management of more than 600,000 workers at more than 6,000 workplaces. Yet their service qualities are different since their backgrounds of foundation are diverse. Therefore many experts keenly feel the necessity, as the Association of Occupational Health Management Agencies suggests, to standardize their services ${ }^{3 !}$.

The results of regular health examinations show us that liver disease is one of the most common diseases among workers $^{4-7}$. Therefore the management of liver disease is among the most important services provided by occupational health nurses. Workers diagnosed with liver disease usually receive counselling, education and guidance from occupational health nurses, so that occupational health services rely much on nurses, and their services need to be standardized.

In the hope of contributing to the standardization of occupational health services, this study was conducted to develop a tool with which we can evaluate the services 
provided by occupational health nurses for the management of liver disease.

\section{Methods}

\section{Development of the initial tool}

The first thing we did to develop the initial tool was to interview 5 nurses and 8 workers diagnosed with liver disease. The interviews were conducted between December 1, 1997 and May 31, 1998. The nurses had been working for over a year for occupational health management agencies in Seoul and Kyonggi area. The workers had been working at 8 workplaces in which these nurses served and had been identified as suffering from liver disease through regular medical examinations. Along with the interview, the same workplaces had been under participating observation and at the same time relevant literature had been reviewed. Through the interview, participating observation and literature review, evaluation factors were sampled and the initial tool was made.

\section{Verification of content validity with Delphi method}

1) For a test of content validity, the initial tool was referred to 9 experts: 4 professors (one nursing professor and 3 medical professors), 3 nurses and 2 doctors working for occupational health management agencies.

2) For a test of content validity, the results of the experts' verification were referred again to 20 workers diagnosed with liver disease who had been working for small or medium sized workplaces.

\section{Composition of evaluation items}

The items were derived from the evaluation factors whose validity had been verified and they were categorized into two: those for nurses and those for workers. Such categorized items were referred again to one professor, 3 nursing Ph. D course students, 3 occupational health nurses and 5 workers, to be reviewed in terms of time required and linguistic expressions.

\section{Completion of the initial tool}

The items in the tool were designed to quantify the evaluation.

\section{Pilot survey}

The completed initial tool was reviewed for the modification of its linguistic expressions, layout and form by 10 workers diagnosed with liver disease and 5 occupational health nurses over $5 \mathrm{yr}$ experience.

\section{Main survey}

The modified tool was referred again to 106 nurses working for occupational health management agencies for over a year and 136 workers diagnosed with liver disease. Thus the tool was redesigned to meet the
First: Development of the initial tool sampling evaluation factors through the interview, participating in observation and literature review

$\downarrow$
Second: Verification of content validity with
Delphi method
(1) referred to 9 experts in this field
(2) referred to 20 workers diagnosed with liver disease
$\downarrow$

Third: Composition of evaluation items

(1) The items were derived from the evaluation factors.

(2) The expression and time required for the questionnaire were reviewed by 12 reviewers.

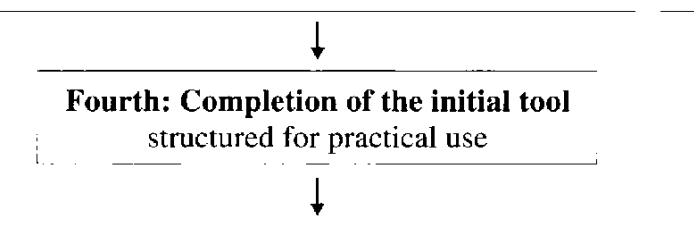

Fifth: Pilot survey

previewed for its linguistic expression, layout and format

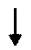

Sixth: Main survey

(1)Internal consistency and structural validity: tested by 106 nurses and 136 workers with liver disease

(2)Test - retest: tested by 61 nurses and 22 workers

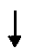

Presentation of the questionnaire

(1) for occupational health nurses

(2) for workers with liver disease

Fig. 1. Procedures used in this study

requirements of consistency and validity, excluding those items which had less than an item-total correlation of 0.15 in terms of Cronbach's alpha coefficients.

Finally the reliability of the tool was tested through a test-retest analysis on 61 nurses and 22 workers randomly selected by the authors.

The collected data were analyzed with SPSS/PC+ for descriptive statistics, Cronbach's alpha coefficients, Pearson correlation coefficients, Spearman's correlation coefficients and multiple regression analysis.

\section{Results and Discussion}

\section{Development of the initial tool}

Through the interviews and participating observation, we could collect 320 statements regarding nursing activities for the management of liver disease. Considering the result of literature review ${ }^{2-7}$, we chose Donnabedian (1978)'s as the most suitable theoretical framework for the classification of those statements. With 
reference to Donnabedian $(1978)^{8)}$, they could be classified into 39 evaluation factors: 24 structure factors, 11 process and 4 outcome factors.

\section{Verification of content validity with Delphi method \\ 1) After the experts' review;}

The two factors, "Influence of working environment on liver disease" and "Supply of protective equipment", were excluded, because they proved to be insignificant even in the case of chronic liver diseases.

One factor was incorporated into another: "Workers" awareness of the health care management system at their workplace" was thought to be redundant with "Usefulness of the health care management system". The former was therefore incorporated into the latter.

As a result, the number of factors was adjusted from 39 to 36 after the experts' review.

2) After the referral to 20 workers diagnosed with liver disease, more than $80 \%$ of the respondents rated the above 36 factors ' 6 points' or higher on the ' 10 -point scale'. According to the criteria of Lynn (1986) ${ }^{9}$, therefore, all of them were adopted.

\section{Composition of evaluation items}

1) First we distinguished between the evaluation tool for nurses and that for workers and selected the items for the respective tool out of the 36 factors whose content validity had been verified. 1-3 items were derived from each factor; In the case of the tool for nurses, 20 and 8 items (a total of 28) were derived from structure and process factors, respectively, and in the case of the tool for workers, 12 and 7 items (a total of 19) were derived from process and outcome factors, respectively.

2) The derived items were then composed into sentences to be numbered and were referred again to 12 reviewers: one nursing professor, 3 nursing $\mathrm{Ph}$. D course students, 3 occupational health nurses and 5 workers. They reviewed them in terms of communicative errors and responding time. They recommended that some expressions be replaced with legally acceptable, easier, and more practical ones. Accepting their recommendations, we made some revisions: "nurse" was replaced with "health manager", "change of seriousness perceived about liver disease" with "awareness of the importance of the management of liver disease", "change of the results of laboratory tests" with "change of numerical values in medical examinations" and so on. As for responding time, both nurses and workers took ten minutes or so to fill out the questionnaire, which proved to be appropriate.

\section{Completion of the initial tool}

On the basis of Likert's '5-point' scale, all the items in the tool were designed to be on a '5-point' scale. And then, on the assumption that the weight of structure, process and outcome factors is roughly the same, in the case of the tool for nurses, the items related to structure factors and those related to process ones were each rated 50 points (total of 100 points altogether). Similarly, in the case of the tool for workers, the items related to process factors and outcome ones were each rated 50 points (total of 100 points altogether). Therefore, if a nurse got full points for 20 structure factors and 8 process ones, her score would be calculated like this: $\{(5 \times 20) \times$ $50 \div(5 \times 20)\}+\{(5 \times 8) \times 50 \div(5 \times 8)\}=100$. In the same way, the score for a worker who got full points for 12 process factors and 7 outcome ones would be calculated as $\{(5 \times 12) \times 50 \div(5 \times 12)\}+\{(5 \times 7) \times 50 \div$ $(5 \times 7)\}=100$. We can formulate this calculation as follows: <in case of the tool for nurses> \{ sum total of the points for structure factors $\times 50 \div(5 \times$ number of structure factors) $\}+$ sum total of the points for process factors $\times 50 \div(5 \times$ number of process factors $)\}$; <in the case of the tool for workers $>$ \{ sum total of the points for process factors $\times 50 \div(5 \times$ number of process factors $)\}+$ \{sum total of the points for outcome factors $\times 50 \div(5 \times$ number of outcome factors) .

In addition, in order to ensure a faithful response from nurses and workers, the tool form was organized to be of a single page and simple, while those regarding the general characteristic variables were laid out at the end. Of course the questionnaire for nurses was separate from that for workers.

\section{Pilot survey}

The completed tool was previewed by 5 occupational health nurses and 10 workers with liver disease. It took them 10-15 min to check the questionnaire. There was no error found in terms of linguistic expressions, and the format turned out to be suitable.

\section{Main survey}

1) General characteristics of respondents

As shown in Table 1, the average age of the occupational health nurses was 31 , and those in their 20 s and $30 \mathrm{~s}$ accounted for the majority (more than $80 \%$ ). Their average career length was 39 months. The average age of the workers was 39.

2) Evaluation tool for nurses

(1) Internal consistency

3 items out of 28 were excluded as their item-total correlations were very low $(0.0857,0.0978$ and 0.0985 , respectively); "Will you report to the manger in charge what you have found during your tour check in the workplace?", "Do you think it is important for workers not to drink in order to manage their liver disease?" and "Do you think all the documents on health examinations and health care management are well kept at the workplace?". As shown in Table 2, the internal consistency of the total 25 items finally selected was 
Table 1. General characteristics of respondents

\begin{tabular}{|c|c|c|}
\hline Respondents & Variables & Number $(\mathscr{F})$ \\
\hline \multirow[t]{8}{*}{ nurses } & age $(y r)$ & $106(100.0)$ \\
\hline & under 29 & $29(27.4)$ \\
\hline & $30-34$ & $43(40.5)$ \\
\hline & over 35 & $34(32.1)$ \\
\hline & experience (months) & \\
\hline & under 24 & $41(38.7)$ \\
\hline & $25-48$ & $36(33.9)$ \\
\hline & over 49 & $29(27.4)$ \\
\hline \multirow[t]{12}{*}{ workers } & age $(y r)$ & $136(100.0)$ \\
\hline & under 34 & $50(36.8)$ \\
\hline & $35-44$ & $52(38.2)$ \\
\hline & over 45 & $34(25.0)$ \\
\hline & \multicolumn{2}{|l|}{$\operatorname{sex}$} \\
\hline & male & $129(94.9)$ \\
\hline & female & $7(5.1)$ \\
\hline & \multicolumn{2}{|l|}{ type of industry* } \\
\hline & 1 & $43(31.6)$ \\
\hline & 2 & $43(31.6)$ \\
\hline & 3 & $3(2.2)$ \\
\hline & 4 & $47(34.6)$ \\
\hline
\end{tabular}

*type of industry: 1. foodstuffs, oil, wood, furniture, pulps, printing, publishing. 2. chemistry, oil refining, plastic, nonmetal working. 3. first metalworking, construction metalworking. 4. machine industry, electricity - machine industry, traffic equipment, precision machine industry.

Cronbach's alpha $=0.7709$, which was deemed quite consistent.

(2) Test-retest reliability

As shown in Table 3, the Pearson correlation coefficient for test - retest was $r=0.718(p<.01)$, which means that any repetition of the test would be likely to give the same result. The tool therefore proved to be quite reliable.

(3) Constituent validity

As shown in Table 4, the two sub-factors 'knowledge' and 'attitude' of the process factor were found to be roughly correlated with the structure factor $(r=0.128$, $\mathrm{r}=0.409$, respectively) but lower, which means that the two sub-factors are relatively independent of each other.

As shown in Table 5, the $\mathrm{R}^{2}$ of structure and process factors was found to be 851 , which implies that $85 \%$ of the tool's variation can be explained with these two factors and, therefore, that the constituent validity of the tool is high.

3) Evaluation tool for workers

(1) Internal consistency

2 items out of 19 were excluded as their item-total correlations were low ( 0.0071 and 0.0414 , respectively); "Are you more concerned with nutrition since being
Table 2. Internal consistencies in the tool for nurses

\begin{tabular}{|c|c|c|c|c|}
\hline $\begin{array}{l}\text { Evaluation } \\
\text { factor }\end{array}$ & $\begin{array}{c}\text { Item } \\
\text { number }\end{array}$ & $\begin{array}{c}\text { Correlation } \\
\text { with total }\end{array}$ & $\begin{array}{c}\text { Chronbach's } \\
\text { alpha }\end{array}$ & $\begin{array}{l}\text { Factor } \\
\text { alpha }\end{array}$ \\
\hline \multirow[t]{18}{*}{ Structure } & 1 & .363 & .760 & \multirow{18}{*}{.812} \\
\hline & 2 & .511 & .759 & \\
\hline & 4 & .471 & .760 & \\
\hline & 5 & .474 & .760 & \\
\hline & 6 & .300 & .764 & \\
\hline & 7 & .427 & .761 & \\
\hline & 8 & .394 & .762 & \\
\hline & 12 & .293 & .764 & \\
\hline & 13 & .345 & .761 & \\
\hline & 19 & .324 & .763 & \\
\hline & 20 & .235 & .766 & \\
\hline & 21 & .349 & .762 & \\
\hline & 22 & .227 & .767 & \\
\hline & 23 & .522 & .754 & \\
\hline & 24 & .238 & .766 & \\
\hline & 26 & .181 & .769 & \\
\hline & 27 & .338 & .762 & \\
\hline & 28 & .291 & .764 & \\
\hline process: & 10 & .311 & .764 & \multirow[t]{2}{*}{.629} \\
\hline knowledge & 11 & .208 & .780 & \\
\hline process: & 14 & .250 & .766 & \multirow{5}{*}{.713} \\
\hline \multirow[t]{4}{*}{ attitude } & 15 & .326 & .765 & \\
\hline & 16 & .403 & .761 & \\
\hline & 17 & .417 & .759 & \\
\hline & 18 & .370 & .763 & \\
\hline total & & & & .770 \\
\hline
\end{tabular}

diagnosed with liver disease?" and "Does liver disease prevent the performance of your duties at the workplace?" As shown in Table 6, the internal consistency of the total of 17 items finally selected was Cronbach's alpha $=0.7588$, which was deemed quite internally consistent.

(2) Test-retest reliability

As shown in Table 7, the Pearson correlation coefficient of test - retest was $r=0.788(p<.01)$, which implies that any repetition of the test would be likely to give the same result, and therefore the stability of the tool is high.

(3) Constituent validity

As shown in Table 8, the correlation between process and outcome factors was found to be very low $(r=0.015)$, which means that the two factors are relatively independent of each other.

As shown in Table 9, the $\mathrm{R}^{2}$ of process and outcome factors was found to be 936 , which implies that $93.6 \%$ of the tool's variation can be explained with these two factors, and therefore the constituent validity of the tool is high. 
Table 3. Test - retest correlation in the tool for nurses

\begin{tabular}{|c|c|c|c|c|}
\hline \multirow{2}{*}{ Retest } & \multirow{2}{*}{ Structure } & \multicolumn{2}{|c|}{ Process } & \multirow[t]{2}{*}{ Total } \\
\hline & & knowledge & attitude & \\
\hline structure & $.627^{* *}$ & & & \\
\hline process : knowledge & & $.551 * *$ & & \\
\hline : attitude & & & $.642 * *$ & \\
\hline total & & & & $.718^{* * *}$ \\
\hline
\end{tabular}

${ }^{*} \mathrm{p}<0.05, * * \mathrm{p}<0.01$. Structure is related to workplace environment, management system for liver diseases in occupational health management agencies and major activities of occupational health nurses.
Table 4. Correlation between evaluation factors in the tool for nurses

\begin{tabular}{lccc}
\hline $\begin{array}{c}\text { Evaluation } \\
\text { factors }\end{array}$ & Structure & \multicolumn{2}{c}{ Process } \\
\cline { 2 - 4 } structure & & knowledge attitude \\
process: knowledge & 1.000 & & \\
$\quad$ : attitude & .128 & 1.000 & \\
\hline
\end{tabular}

${ }^{*} p<0.05$. Structure is related to workplace environment, management system for liver diseases in occupational health management agencies and major activities of occupational health nurses.

Table 5. Stepwise multiple regression of evaluation factors in the tool for nurses

\begin{tabular}{|c|c|c|c|c|c|}
\hline Step & variables & $\mathbf{R}^{2}$ & $\beta$ & $\mathrm{df}$ & $\mathbf{F}$ \\
\hline 1 & structure factor & .596 & .689 & $1 / 104$ & $155.6^{* *}$ \\
\hline 2 & process factor: knowledge & .851 & .505 & $2 / 103$ & $300.3^{* *}$ \\
\hline 3 & process factor: attitude & .864 & .200 & $3 / 102$ & $215.4^{* *}$ \\
\hline
\end{tabular}

$* \mathrm{p}<0.05, * \mathrm{*}<0.01$.

independent variable: structure factor, process factor (knowledge), process factor (attitude) dependent variable: management of liver disease.

Table 6. Internal consistencies in the tool for workers

\begin{tabular}{|c|c|c|c|c|}
\hline $\begin{array}{l}\text { Evaluation } \\
\text { factor }\end{array}$ & $\begin{array}{c}\text { Item } \\
\text { number }\end{array}$ & $\begin{array}{c}\text { Correlation } \\
\text { with total }\end{array}$ & $\begin{array}{c}\text { Chronbach's } \\
\text { alpha }\end{array}$ & $\begin{array}{l}\text { Factor } \\
\text { alpha }\end{array}$ \\
\hline \multirow[t]{12}{*}{ process } & 1 & .391 & .743 & \multirow{12}{*}{.845} \\
\hline & 2 & .431 & .741 & \\
\hline & 3 & .316 & .750 & \\
\hline & 4 & .487 & .735 & \\
\hline & 5 & .644 & .716 & \\
\hline & 6 & .532 & .733 & \\
\hline & 7 & .665 & .724 & \\
\hline & 8 & .673 & .719 & \\
\hline & 9 & .387 & .744 & \\
\hline & 10 & .589 & $.73 \mathrm{I}$ & \\
\hline & 11 & .379 & .744 & \\
\hline & 12 & .335 & .748 & \\
\hline \multirow[t]{5}{*}{ outcome } & 13 & .217 & .759 & \multirow{5}{*}{.561} \\
\hline & 14 & .238 & .755 & \\
\hline & 15 & .273 & .749 & \\
\hline & 16 & .266 & .754 & \\
\hline & 17 & -.206 & .793 & \\
\hline Total & & & & .758 \\
\hline
\end{tabular}

Table 7. Test - retest correlation in the tool for workers

\begin{tabular}{cc}
\hline & Test \\
\cline { 2 - 2 } Retest & $.788^{* *}$ \\
\hline${ }^{*} \mathrm{p}<0.05,{ }^{* *} \mathrm{p}<0.01$.
\end{tabular}

Table 8. Correlation between evaluation factors in the tool for workers

\begin{tabular}{crc}
\hline Evaluation factor & Process & Outcome \\
\hline $\begin{array}{c}\text { Process } \\
\text { outcome }\end{array}$ & 1.000 & \\
\hline
\end{tabular}

$\approx p<0.05$. 
Table 9. Stepwise multiple regression of evaluation factors in the tool for workers

\begin{tabular}{cccccc}
\hline Step & Variables & $\mathrm{R}^{2}$ & $\beta$ & $\mathrm{df}$ & $\mathrm{F}$ \\
\hline $\mathrm{I}$ & process factor & .801 & .862 & $1 / 134$ & $161.8^{* *}$ \\
2 & outcome factor & .936 & .354 & $2 / 133$ & $252.0^{* *}$ \\
\hline
\end{tabular}

${ }^{*} \mathrm{p}<0.05,{ }^{* *} \mathrm{p}<0.01$.

independent variable; process factor, outcome factor

dependent variable; management of liver disease.

Table 10. Final items in the questionnaire for nurses*

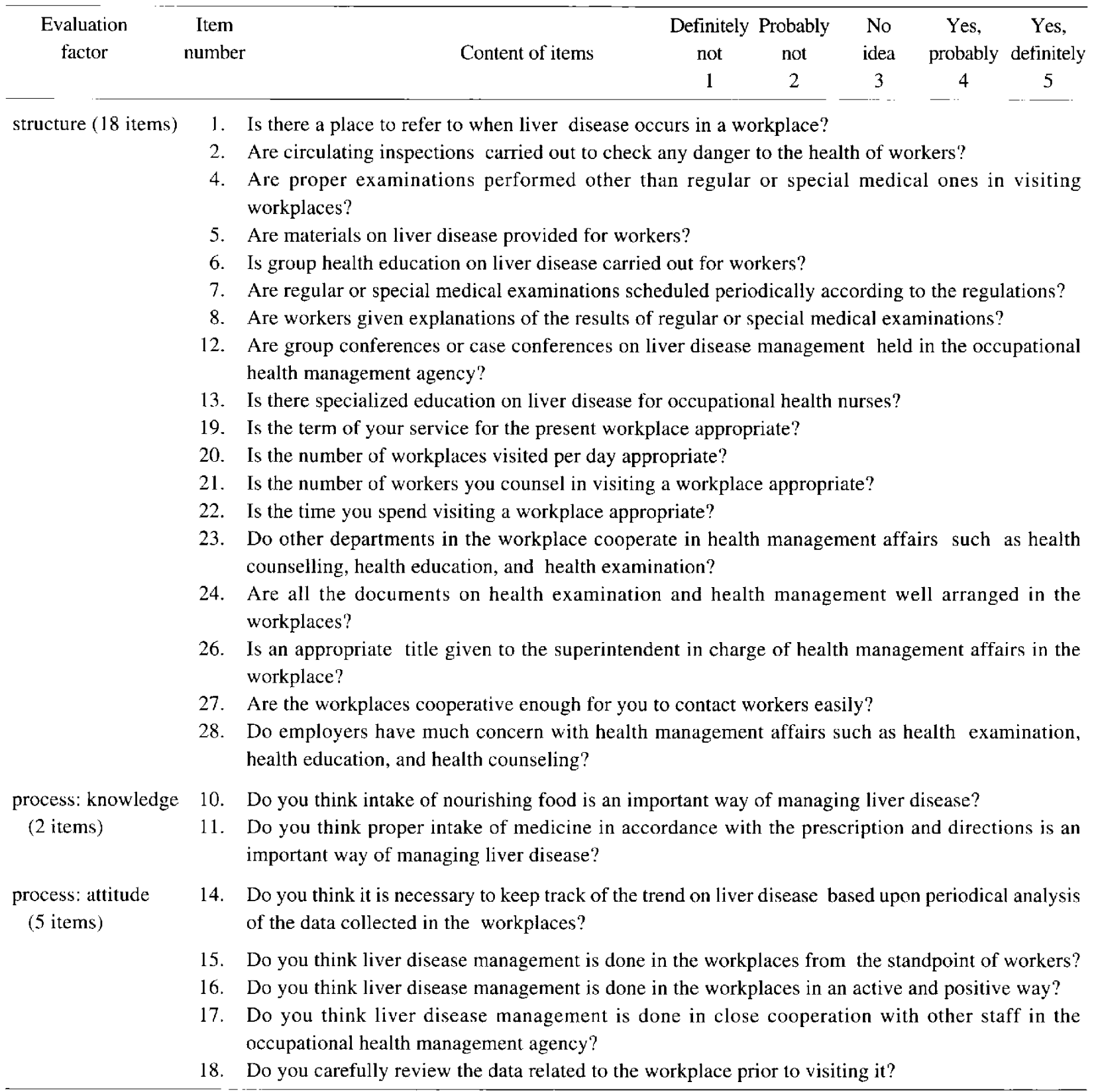

${ }^{*}$ workplace environment; 1, 17, 18, 20, 21, 22.

management system for liver disease in the occupational health management agency; $4,10,13,14,15,16$,

main work; $2,5,6,7,8$. 
Table 11. Final items in the questionnaire for workers

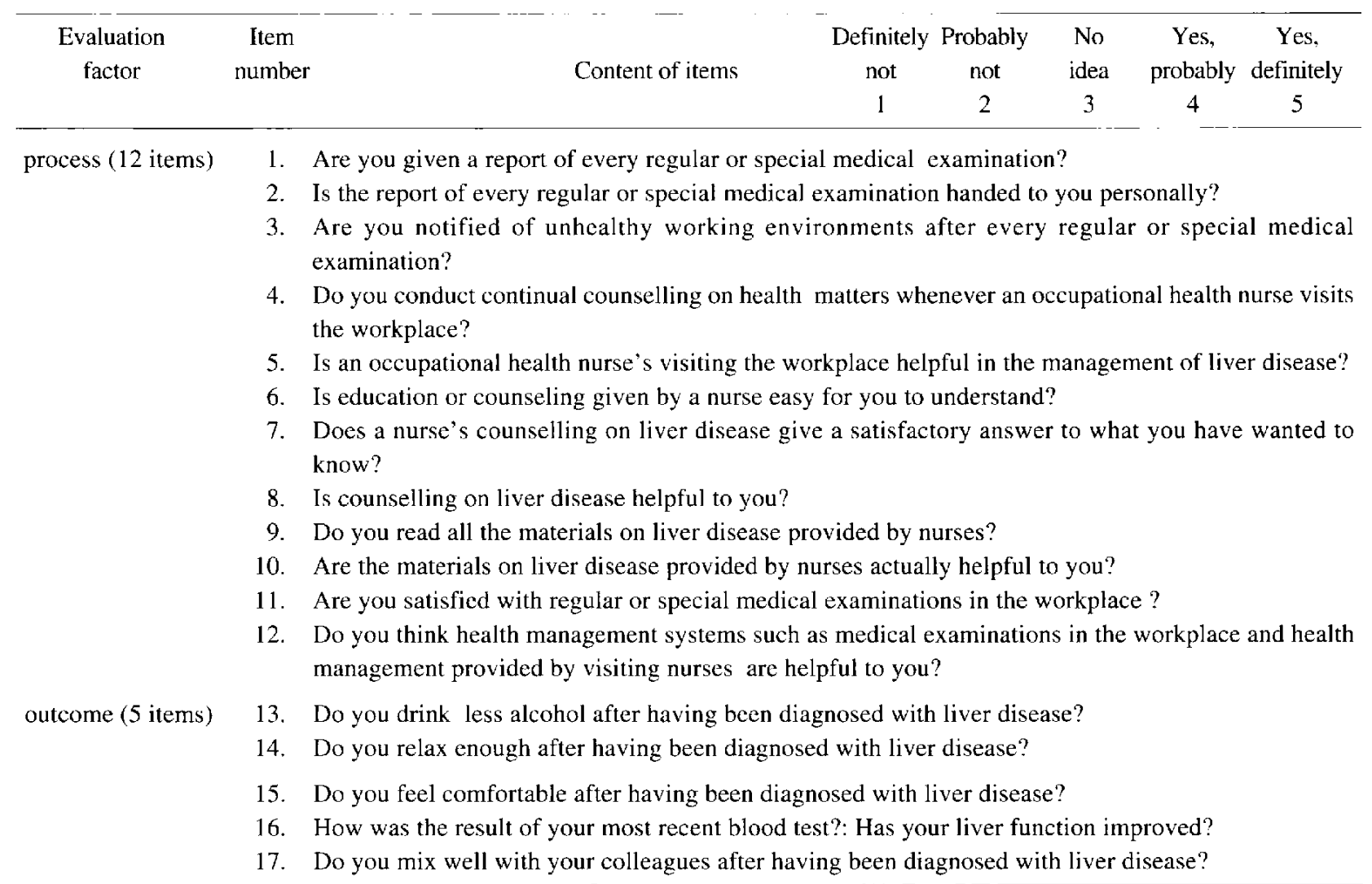

\section{Presentation of the questionnaires}

Tables 10 and 11 show the final items in the questionnaires we developed as an evaluation tool for the management of liver disease. We hope that they will be practically available for the evaluation of nursing activities at workplaces and that they will contribute to the standardization of occupational health services provided by occupational health management agencies.

This paper was orally presented at the Twelfth JapanKorea Joint Conference on Occupational Health in Okayama, Japan on May 21-22, 1999.

\section{References}

1) Department of Industrial Health, Ministry of Labor, Korea. Collections of recent regulations on industrial health and safety. Seoul: Department of Industrial Health, 1998: 3-20 (in Korean).

2) Lee MS, Jung MH, Moon JS, et al. Occupational health nursing services in cooperation with community health services for small scale industries. Abstracts. Okayama, Japan: The twelfth Japan-Korea joint conference on occupational health, 21-22 May 1999; p 35.

3) Park JI, Kim KS, Kim HO, et al. Mannual of health managers by function for group health practice. Seoul, Association of Occupational Health Management Agencies, 1977: 83-134 (in Korean).

4) Korea Ministry of Labor. ' 97 Survey report of establishment of labor conditions. Seoul, 1998 (in Korean).

5) Kim SG and Park JI. Factors related to postmanagement performance of workers with general disease in small and medium sized enterprise. The Kor J Occup Med 1993; 5: 274-282 (in Korean with English abstract).

6) National Statistical Office, Republic of Korea. 1997 social indicators in Korea. Seoul: National Statistical Office 1997: p 280 (in Korean).

7) Park JS, Km YH. The history of occupational health service in Korea. Industrial Health 1998; 36: 393-401.

8) Donnabedian, A. Quality assessment and assurance: unity of purpose, diversity of means. Inquiry 1988: 25: 173-192.

9) Lynn MR.Determination and quantification of content validity. Nur Res 1986; 35: 382-385. 